\begin{tabular}{|c|l|}
\hline Title & Sea Level Pressure Minimum along the Kuroshio and Its Extension \\
\hline Author(s) & Tanimoto, Youichi; Kanenari, Tomohisa; Tokinaga, Hiroki; Xie, Shang-Ping \\
\hline Citation & Journal of Climate, 24(16), 4419-4434 \\
\hline https://doi.org/40.1175/2011CLI4062.1 \\
\hline Issue Date & 2011-08 \\
\hline Doc URL & http://hdl.handle.net/2115/48175 \\
\hline Rights & ○ 2011 A merican Meteorological Society \\
\hline Type & article \\
\hline File Information & JoC24 16_4419-4434.pdf \\
\hline
\end{tabular}

Instructions for use 


\title{
Sea Level Pressure Minimum along the Kuroshio and Its Extension*
}

\author{
YOUICHI TANIMOTO \\ Faculty of Environmental Earth Science, and Graduate School of Environmental Science, Hokkaido University, Sapporo, \\ and Research Institute for Global Change, JAMSTEC, Yokohama, Japan \\ TOMOHISA KANENARI \\ Faculty of Environmental Earth Science, and Graduate School of Environmental Science, Hokkaido University, Sapporo, Japan \\ HIROKI TOKINAGA \\ International Pacific Research Center, University of Hawaii at Manoa, Honolulu, Hawaii \\ SHANG-PING XIE \\ International Pacific Research Center, and Department of Meteorology, University of Hawaii at Manoa, Honolulu, Hawaii
}

(Manuscript received 9 September 2010, in final form 10 February 2011)

\begin{abstract}
Atmospheric effects of sea surface temperature (SST) fronts along the Kuroshio and Kuroshio Extension (K-KE) are investigated by examining spatial characteristics of the climatological sea level pressure (SLP), surface winds and surface heat flux $(Q)$ fields based on an in situ observation dataset. A hydrostatic effect of the SST front is observed during the northwesterly monsoon characterized by a westward-extending low-SLP wedge (trough) slightly south of the peak in $Q$ along the K-KE. Ageostrophic surface westerlies crossing SLP isobars toward a trough center are found north of the low-SLP wedge apparently because of the eastward acceleration by the vertical mixing effect. This feature of the ageostrophic winds is less pronounced south of it, a north-south asymmetry arising as vertical mixing accelerates (decelerates) eastward ageostrophic winds north (south) of it. While the SLP trough near the SST front is found nearly year-round except for summer, its meridional location seasonally migrates probably due to the change in the mean surface flow.

Regional atmospheric model experiments are conducted to examine the effect of the SST front on the overlying atmosphere. The observed features in winter are adequately simulated when high-resolution SST is prescribed as the boundary condition. The strong $Q$ along the K-KE and resultant SLP trough and ageostrophic surface winds are absent when the SST boundary condition is smoothed in space to weaken the SST front. These results illustrate that the cross-frontal change in $Q$ is of great importance to leave the SST imprint on the overlying atmosphere via hydrostatic and vertical mixing adjustments.
\end{abstract}

\section{Introduction}

Atmospheric responses in the marine atmospheric boundary layer (MABL) to sea surface temperature (SST)

\footnotetext{
* International Pacific Research Center Publication Number 764 and School of Ocean and Earth Science and Technology Publication Number 8105.

Corresponding author address: Dr. Youichi Tanimoto, Faculty of Environmental Earth Science, Hokkaido University, N10 W5, Kita-ku, Sapporo, Hokkaido 060-0810, Japan.

E-mail: tanimoto@ees.hokudai.ac.jp
}

have been mostly investigated with a focus on the surface wind changes across the SST fronts. Lindzen and Nigam (1987) propose a hydrostatic effect of the tropical SST on the overlying sea level pressure (SLP) field through changes in air temperature in the MABL. The resultant SLP gradient across the SST front causes wind adjustment at the sea surface, with the strongest wind response found between the warm and cold SST. On the other hand, Wallace et al. (1989) and Hayes et al. (1989) propose a vertical mixing effect in which warm (cold) SST decreases (increases) the near-surface static stability and thereby enhances (reduces) a vertical mixing in the MABL. This effect induces the strongest wind adjustments 
on the warm flank of the SST front where the downward transfer of large momentum from the upper MABL accelerates the surface winds.

Small et al. $(2003,2005)$ examined SST effects on the surface winds by analyzing the momentum budget in a regional atmospheric model (RAM). They found that the hydrostatic effect is a major factor in driving crossfrontal change in surface winds. Under the advection by the mean southeasterly trade winds, the SLP gradient is located downstream of the SST gradient, giving rise to strongest winds on the downwind side of the SST front. The analysis of buoy measurements by Cronin et al. (2003) supports the hydrostatic effect on SLP. In situ observations by Hashizume et al. (2002) and East Pacific Investigation of Climate Processes in the Coupled Ocean-Atmosphere System (EPIC) campaign (Raymond et al. 2004), however, indicate that the vertical mixing effect is at work in the acceleration of the surface winds.

The study of the atmospheric responses to the SST front has been extended to midlatitude SST fronts and mesoscale eddies (Xie 2004; Small et al. 2008). Owing to large temperature and moisture differences between ocean and atmosphere, fronts anchor the local maximum of upward surface heat flux that can act to induce hydrostatic and vertical mixing effects in the MABL. Satellite measurements of the surface winds display divergence when the winds go across the SST front and wind curl when they blow along the fronts in the extratropics (O'Neill et al. 2003; Chelton et al. 2004; Vecchi et al. 2004; O'Neill et al. 2005; Tokinaga et al. 2005; Park et al. 2006). These wind adjustments are consistent with the vertical mixing effect around the SST front. In contrast, the hydrostatic adjustment is also suggested from analyses of the in situ surface meteorological observations, satellite measurements, and operational and reanalysis datasets of the lower atmosphere. Over the warm flank of the Kuroshio Extension (KE), Tokinaga et al. (2009) show a zonal band of the local minimum in spatially high-pass-filtered SLP anomalies in association with positive MABL temperature anomalies and vice versa over the cold flank of it. More recently, Minobe et al. $(2008,2010)$ suggest that the hydrostatic adjustment along the Gulf Stream leads to convective cloud formation and enhanced precipitation. Song et al.(2006) show that, based on the RAM experiments, pressure gradient across the Gulf Stream front is main force modifying the surface winds. Xu et al. (2010) also detected a hydrostatic effect over the cool water pool formed between the Pacific coast of Japan and the large meander of the Kuroshio.

In the western North Pacific, tropospheric circulation is highly monsoonal (Fig. 1), bringing about a distinct seasonal cycle in surface heat flux. The present study examines how the monsoonal flow over the western boundary current region is modified when it crosses a midlatitude SST front. By careful inspections of spatial characteristics in the SLP and surface wind fields during each season, we attempt to detect hydrostatic and vertical mixing effects. These ocean imprints on the lower atmosphere are further examined using RAM experiments.

While the Japanese 25-yr Reanalysis (JRA-25) (Onogi et al. 2007) still does not adequately resolve small-scale features near ocean fronts, direct measurements of SLP on merchant ships have been carried out along the busy shipping lanes in the Pacific near Japanese islands (e.g., Fig. 2b in Tokinaga et al. 2009). The present study compares reanalysis and in situ measurements to study smallscale SLP features over the western North Pacific.

The rest of this paper is organized as follows. Section 2 introduces the datasets and model used in the present study. Section 3 examines spatial characteristics of the SLP and surface wind fields in the western North Pacific during the winter and summer monsoon, respectively, and make a comparison of those characteristics between reanalysis and in situ measurements. Section 4 discusses the ocean imprint near the SST front on the overlying atmosphere based on RAM experiments. Section 5 is summary and discussion.

\section{Data and model}

\section{a. In situ observations}

We use a monthly product of the International Comprehensive Ocean-Atmosphere Dataset (ICOADS) release 2.4 (Worley et al. 2005) from January 1950 to December 2007, available on a $1^{\circ}$ grid. Individual surface meteorological measurements from ships, buoys, and other marine platforms are gridded after careful quality controls. Further description of the data processing is documented in Tokinaga et al. (2009). We calculate monthly climatology of SST, surface air temperature (SAT), surface wind velocity, latent and sensible surface heat fluxes, and SLP by averaging data from 1950 to 2007 in the western North Pacific $\left(20^{\circ}-50^{\circ} \mathrm{N}, 120^{\circ}-170^{\circ} \mathrm{E}\right)$.

We will examine the sum of latent and sensible surface heat fluxes $Q$ of ICOADS as an indicator of the heating of the MABL from the ocean surface. The latent heat flux, in addition to the direct sensible heat flux, may contribute to the warming of the MABL in the Kuroshio and Kuroshio Extension (K-KE) region where the midlatitude storms are developed, accompanied with the zonal rainband and low-level clouds. The ocean surface heat flux dataset based on satellite measurements [Japanese Ocean Flux Datasets with Use of Remote Sensing Observations version 2 (J-OFURO2); Kubota et al. 2002; Tomita et al. 2010] provides the latent, sensible, and radiative heat fluxes. Their seasonal climatology during 1993-2006 shows that, 


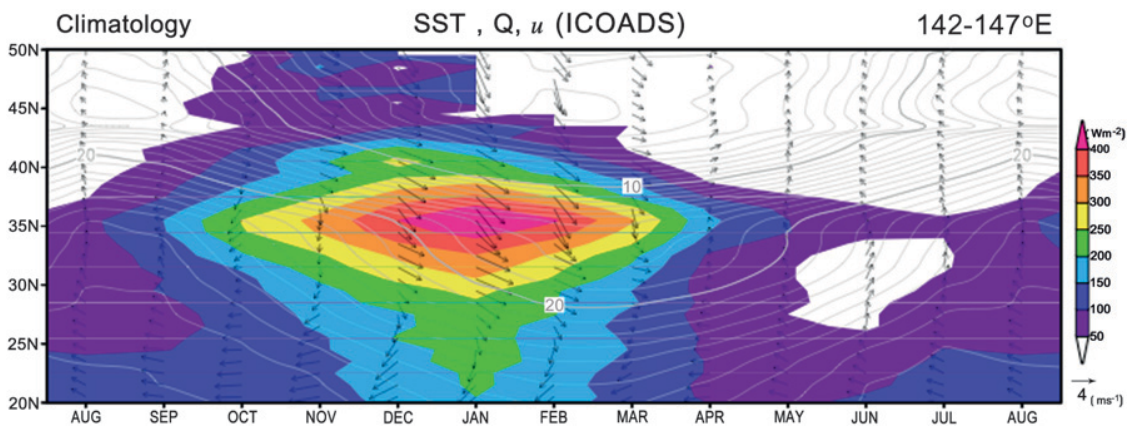

FIG. 1 . Monthly climatology of SST [gray contours; contour interval $(\mathrm{CI})=1^{\circ} \mathrm{C}$ ], $Q$ (colors; $\mathrm{W} \mathrm{m}{ }^{-2}$ ), and surface winds (arrows; $\mathrm{m} \mathrm{s}^{-1}$ ) averaged over $142^{\circ}-147^{\circ} \mathrm{E}$ based on ICOADS. Note that the horizontal axis begins and ends in August. Color convention and scale of arrows are represented on the right.

in the $\mathrm{K}-\mathrm{KE}$ region, $Q$ is the predominant term in the meridional maximum of the net surface heat exchange from autumn through winter to spring (Fig. 2). In the aerodynamic bulk formulae, sensible and latent heat fluxes are a function of temperature difference between ocean and atmosphere $\Delta T_{\mathrm{OA}}$ and moisture difference, respectively. In the present study, we employ only $\Delta T_{\mathrm{OA}}$ as an indicator of these differences because surface moisture in the atmosphere strongly depends on local air temperature (Kleeman and Power 1995; Tanimoto et al. 2003).

As stated in introduction, the prevailing surface wind over the western North Pacific display a pronounced seasonal cycle. In the monthly climatology of ICOADS, the meridional component of extratropical surface winds averaged over $142^{\circ}-147^{\circ} \mathrm{E}$ changes its sign twice a year, between March and April and between September and October, respectively (Fig. 1). Therefore, we will examine northwesterly and southwesterly monsoons separately. In the northwesterly (southwesterly) monsoon, threemonth means are calculated with October-December as autumn and January-March as winter (April-June as spring and July-September as summer), following studies in the North Pacific (Suga and Hanawa 1995; Deser et al. 1996; Schneider et al. 1999; Tourre et al. 1999; Sugimoto and Hanawa 2007).

\section{b. Reanalysis products (JRA-25)}

We employ the monthly JRA-25 from January 1979 to December 2004, available on $1.25^{\circ}$ grid (Onogi et al. 2007). From 2005 to 2007, we use the monthly product of the operational analysis provided by Japan Meteorological Agency Climate Data Assimilation System (JCDAS), which uses the same data assimilation system as in JRA-25 and has been used for near real-time climate monitoring (Onogi et al. 2007). The variables include wind velocity, (a)

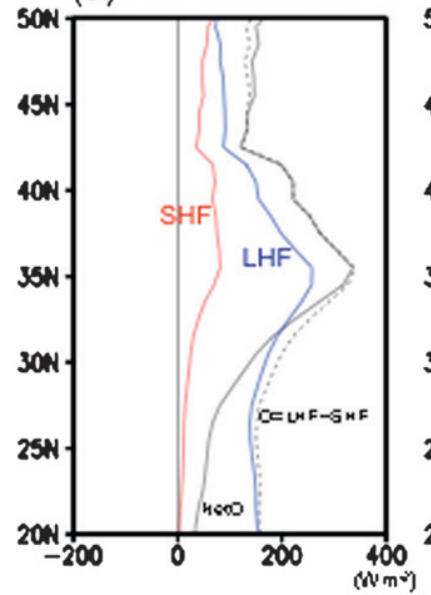

(b)

Climatology (J-OFURO2) $142-147^{\circ} \mathrm{E}$

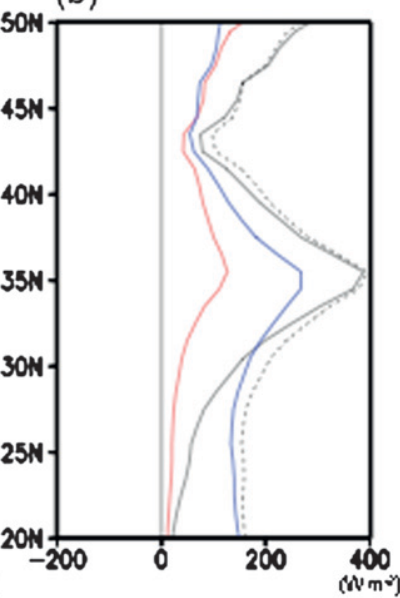

(c)

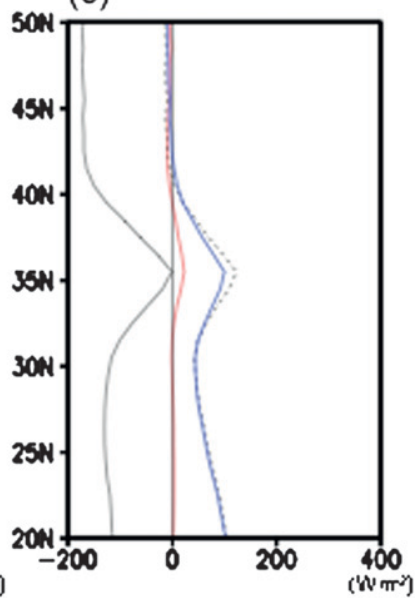

(d)

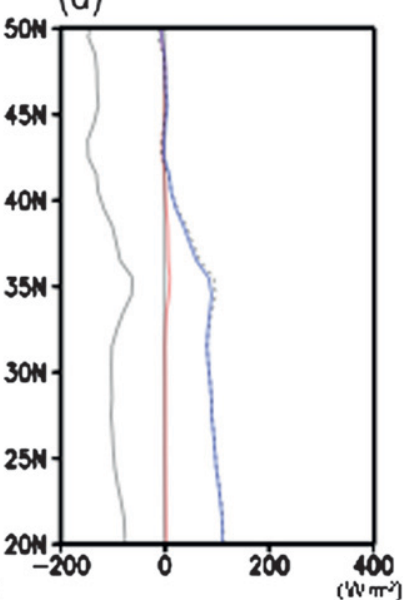

FIG. 2. Seasonal mean sensible (red), latent (blue), $Q$ (dashed black), and Qnet (solid black) based on J-OFURO2 for (a) autumn, (b) winter, (c) spring, and (d) summer averaged over $142^{\circ}-147^{\circ} \mathrm{E}$. 
latent and sensible heat fluxes, and SLP. Monthly climatology is calculated by averaging from 1979 to 2007.

\section{c. Regional atmospheric model experiment}

To identify the ocean imprint on the overlying atmosphere, we conduct experiments using the Weather Research and Forecasting (WRF) model version 3.1 with the Advanced Research WRF (ARW) dynamic core (Skamarock et al. 2008) in a domain of the western North Pacific $\left(20^{\circ}-50^{\circ} \mathrm{N}, 120^{\circ}-170^{\circ} \mathrm{E}\right)$. The model resolution is $27 \mathrm{~km}$ in the horizontal and 43 sigma levels in the vertical, of which 18 levels are placed below $2 \mathrm{~km}$ high. We chose the following set of the schemes: the asymmetric convective model version 2 (ACM2) planetary boundary scheme (Pleim and Chang 1992), the Betts-Miller-Janjić cumulus parameterization (Betts and Miller 1986; Janjić 1994), the double moment 6-class microphysical scheme (Hong and Lim 2006), and rapid radiative transfer model and Dudhia schemes for longwave and shortwave radiation calculations (Dudhia 1989; Mlawer et al. 1997), respectively.

To examine the effect of the SST front, we conduct two experiments. One is the control (CTRL) run by prescribing 10-day mean SST observed by Advanced Microwave Scanning Radiometer for the Earth Observing System (EOS; AMSR-E) satellite measurements (Wentz and Meissner 2000). AMSR-E data is interpolated from $0.25^{\circ}$ interval to the model's $27-\mathrm{km}$ grid. A daily highresolution SST dataset based on the Advanced Very High Resolution Radiometer (AVHRR) infrared satellite measurements (Reynolds et al. 2007) is also used to cover the coastal regions where AMSR-E SST data are missing. An additional run uses spatially smoothed SST (SMTH) to reduce frontal and small-scale structures in SST. For this SMTH run, we apply a $10^{\circ}$ running mean filter to the observed SST. We should note that the amount of enthalpy flux into the model atmosphere might not be same between the two runs, although this kind of experimental design has been employed in the numerical studies (Nakamura et al. 2008; Taguchi et al. 2009; Xu et al. 2010; Iizuka 2010).

We conduct four sets of 10-day integration separately for each experiment, for 1-10 December 2002, 1-10 January 2003, 1-10 February 2003, and 1-10 March 2003. We avoid long-term model integrations in which we may have difficulty in separating the persistent ocean front's influence from the internal model drift in mean state. Indeed, a 1-month integration displays a weak decreasing drift in the SLP along the K-KE region. We additionally conducted two 1-month runs for December 2002 with and without the 10-daily reinitializations. The December averages of these two runs also display nearly the same pattern of surface heat flux, SLP, and surface wind. This result indicates that the 10-daily reinitializations neither affect the certain patterns in those fields nor give a longterm drift in a continuous integration. We have conducted additional WRF experiments forced by daily SST and by monthly mean SST for 1-31 December 2002. The results are very similar in the surface heat flux, SLP, and surface wind. This is because SST does not change that much in observations over 10 days. Therefore, we will examine the WRF response to the 10-day mean SST during each of months to identify the MABL adjustment to the persistent SST feature. The 2002/03 winter is chosen because the surface heat exchange was very large in the K-KE region on that winter. As for initial and lateral boundary conditions, we employ the National Centers for Environmental Prediction (NCEP) Final Global Analyses on a $1^{\circ} \times 1^{\circ}$ grid. To adjust initial and boundary conditions, the model is initialized at 0000 UTC on one day before the first day of the 10-day integrations. The results in the experiments did not change even if we have the spinup period for 2 or 3 days. The lateral condition is updated at every six hours. For these RAM experiments, winter means averaged over the four sets of 10-day integrations (a total of 40 days) are analyzed.

\section{Observed low pressure wedge over the Kuroshio and its extension}

\section{a. Autumn-winter season in ICOADS}

As expected from the northwesterly monsoon during autumn-winter (Fig. 1), the large-scale feature of the climatological SLP in the western North Pacific (contours in Figs. $3 \mathrm{a}$ and $3 \mathrm{~b}$ ) presents a gradual westward increase. While the large-scale northerlies or northwesterlies advect the cold and dry air mass from the continent in most of the western North Pacific and its marginal seas, the large heat release $\left(Q>200 \mathrm{~W} \mathrm{~m}^{-2}\right)$ is found only along the K-KE region from Taiwan through Japan to the east (color shading in Figs. $3 a$ and $3 b$ ). Figure 1 displays that the steep meridional gradient of SST along the K-KE is found at $35^{\circ}-42^{\circ} \mathrm{N}$, and that the $Q$ maximum is located on the warm flank of the SST front year-round. This is because the frontal structure in SST along the K-KE maintains large $\Delta T_{\mathrm{OA}}$ as observed in the $142^{\circ}-147^{\circ} \mathrm{E}$ longitude band (Figs. $3 \mathrm{c}$ and $3 \mathrm{~d}$ ) together with large moisture differences, even with scalar wind speed nearly uniform in the meridional direction. As found in Fig. 2, the $Q$ maximum accounts for the net heat exchange (Qnet) in the K-KE region. The $Q$ values decrease in the interior region to the east as the frontal structure in SST weakens (Figs. 3e and $3 \mathrm{f}$ ).

A closer look at the SLP distribution in the K-KE region unveils a westward-extending SLP trough (white 


\section{Climatology}

(a) SLP \& $Q$ (ICOADS)

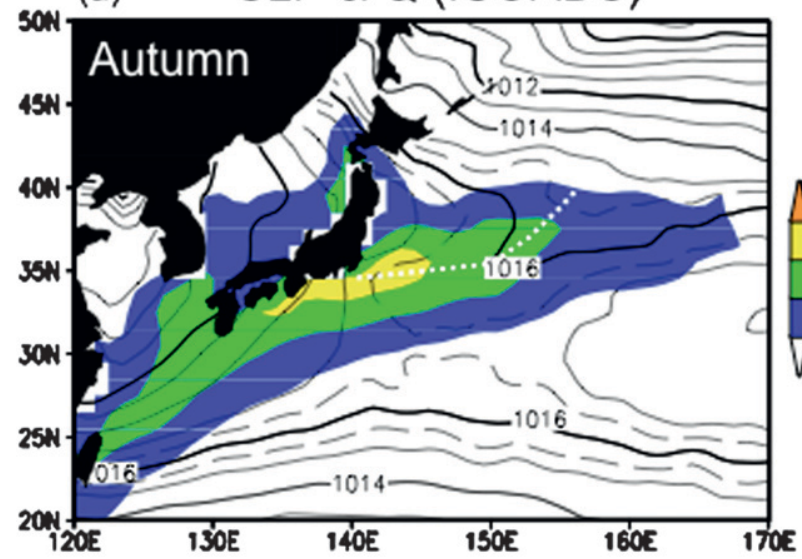

(b) $\quad$ SLP \& Q (ICOADS)

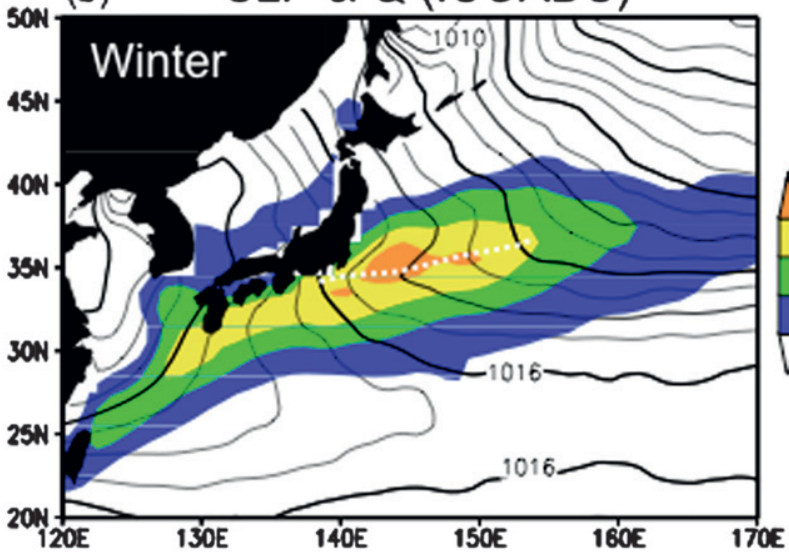

(c) $142-147^{\circ} \mathrm{E}$

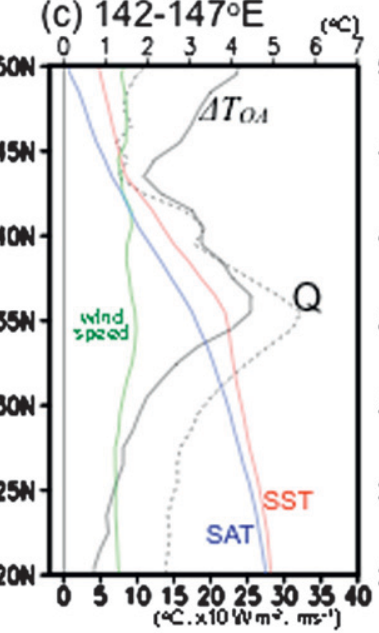

(e) $160-165^{\circ} \mathrm{E}$

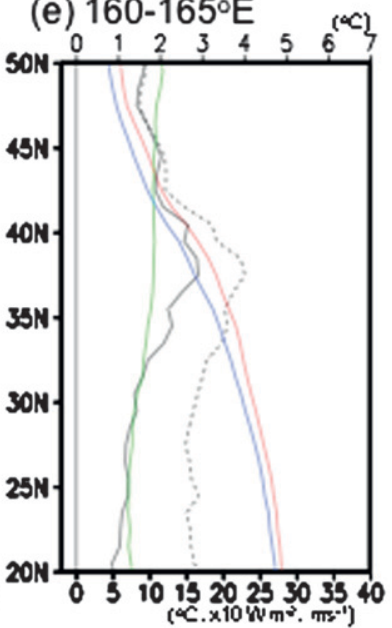

(d) $142-147^{\circ} \mathrm{E}$

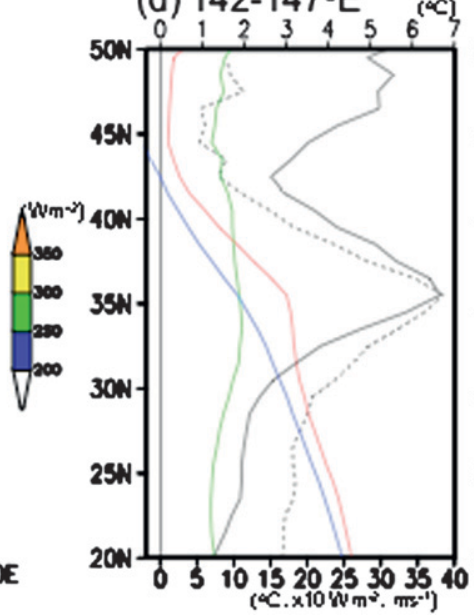

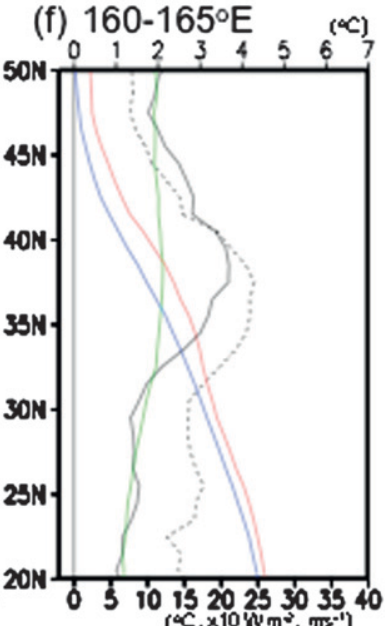

FIG. 3. (a),(c),(e) Autumn and (b),(d),(f) winter climatologies based on ICOADS: (a),(b) Seasonal-mean SLP (black contours; CI = $1 \mathrm{hPa}$ ) and $Q$ (colors; $\mathrm{W} \mathrm{m}^{-2}$ ). Supplemental dashed contours at 0.5 -hPa intervals are plotted. White dashed line indicates the SLP trough in the K-KE region. Coloring convention is given to the right of each panel. (c),(d) Climatological SST (red; ${ }^{\circ} \mathrm{C}$ ), SAT (blue; ${ }^{\circ} \mathrm{C}$ ), surface wind speed (green; $\mathrm{m} \mathrm{s}^{-1}$ ), $Q$ (dotted black; $10 \mathrm{~W} \mathrm{~m}^{-2}$ ), and $\Delta T_{\mathrm{OA}}$ (solid black; ${ }^{\circ} \mathrm{C}$ ) averaged over $142^{\circ}-147^{\circ} \mathrm{E}$. (e), (f) As in (c), (d), but for climatologies averaged over $160^{\circ}-165^{\circ} \mathrm{E}$. Note that the axis for $\Delta T_{\mathrm{OA}}$ is at the top of the panels, but the axis for the other variables is at the bottom of the panels.

dashed line in Figs. 3a and 3b) where the wedge-like shapes pointing to the west are represented by the region between the isobars of $1015.5-1016.5 \mathrm{hPa}$ during autumn and 1012-1016 hPa during winter. The center axis of this westward-extending low-SLP wedge is displaced south of the meridional maximum in $Q$ by about $1^{\circ}$ latitude. The meridional phase relation of the lowSLP wedge and $Q$ maximum is probably due to the thermal advection effect discussed later in the section. While Tokinaga et al. (2009) have shown negative values of spatially filtered anomalies during the (DecemberFebruary) SLP climatology over the KE region based on ICOADS (Tokinaga et al. 2009), we find that the westward-extending low-SLP wedge in the actual (unfiltered) isobars can be observed throughout the northwesterly monsoon. This observational finding indicates the hydrostatic effect, in which the heat release from the ocean acts to warm the overlying atmosphere, results in the visible minimum of SLP via hydrostatic adjustment.

While surface northeasterlies are expected from the geostrophic balance north of the low-SLP wedge, the observed surface winds (black arrows in Fig. 4a) are still westerly across the isobars toward the SLP trough. Ageostrophic flow (red arrows in Fig. 4a), defined as residuals by removing the geostrophic wind from the observed wind, tend to show a large westerly component 


\section{Winter Climatology}

(a) SLP, Q, $\boldsymbol{u}, \boldsymbol{u}$ ag (ICOADS)

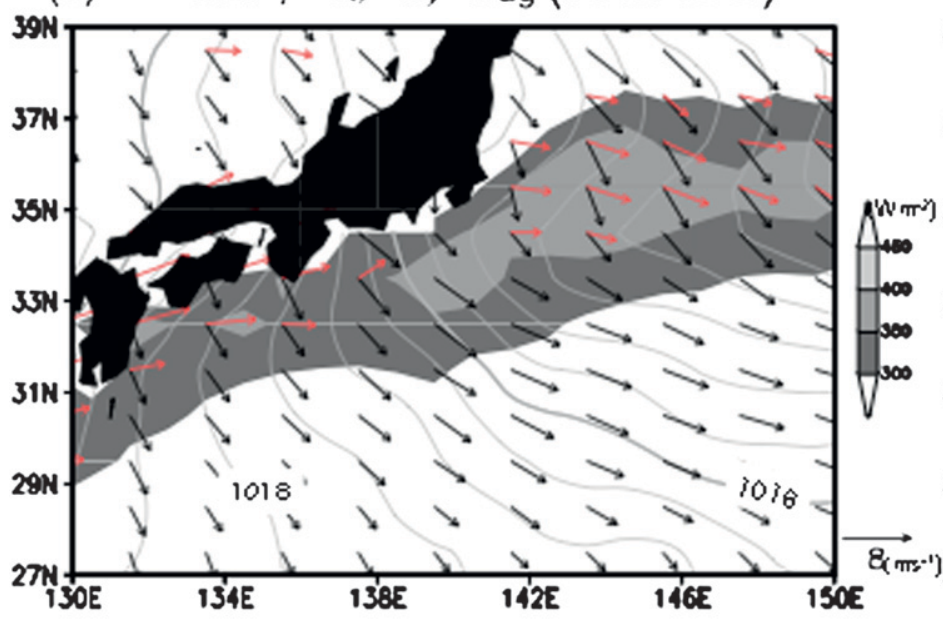

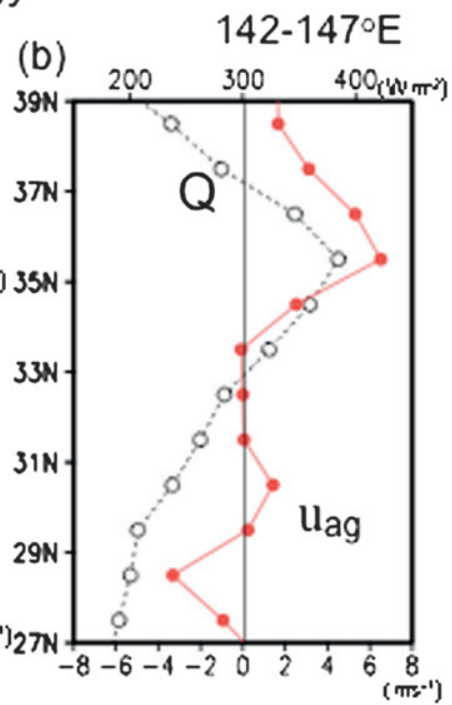

FIG. 4. (a) Winter climatology of surface wind (black arrows; $\mathrm{m} \mathrm{s}^{-1}$ ), and ageostrophic wind (red arrows; $\mathrm{m} \mathrm{s}^{-1}$ ), superimposed on SLP (gray contours; $\mathrm{CI}=0.5 \mathrm{hPa}$ ), and $Q$ (gray shades; $\mathrm{W} \mathrm{m}^{-2}$ ) based on ICOADS. Ageostrophic winds less than $3.5 \mathrm{~m} \mathrm{~s}^{-1}$ are not represented. Shading convention and scale of arrows are represented to the right. (b) Climatological meridional plots of winter means in ageostrophic zonal winds (solid red; $\mathrm{m} \mathrm{s}^{-1}$ ) and $Q$ (dashed black; $\mathrm{W} \mathrm{m}^{-2}$ ) averaged over $142^{\circ}-147^{\circ} \mathrm{E}$ based on ICOADS. Note that the axis for $Q$ is at the top of the panel, but the axis for the ageostrophic zonal winds is at the bottom of the panel.

north of the low-SLP wedge where $Q$ is strongest (Fig. 4b), suggesting that enhanced vertical mixing brings the westerly components aloft to the surface. While the vertical resolution of the JRA-25 is inadequate to represent the MABL adjustment, we note that its climatological winds at the $850-\mathrm{hPa}$ level are westerly (not shown here). In contrast, the ageostrophic winds south of the low-SLP wedge are very weak (Fig. 4) even though $Q$ still exceeds $300 \mathrm{~W} \mathrm{~m}^{-2}$. O'Neill et al. (2010) examined the effect of surface wind direction associated with mesoscale SST variability having spatial scale of 100 $1000 \mathrm{~km}$ and noted a clockwise rotation by $10^{\circ}$ of the surface wind direction over the positive high-passfiltered SST anomalies along the Kuroshio. This finding is consistent with our result about northwesterly ageostrophic winds north of the low-SLP wedge on the warm flank of the SST front.

Let us consider the momentum budget north and south of the low-SLP wedge separately as in the schematic view of Fig. 5. It is a four-way balance among pressure gradient (white arrow in Fig. 5), Coriolis forces (blue arrow), friction (yellow arrow) and vertical momentum mixing (red arrow). North of the low-SLP wedge, eastward acceleration by vertical mixing (red arrow) acts to turn the actual surface wind farther to the left of the geostrophic winds and slightly increases wind speed (Fig. 5c). Thus, the surface friction and vertical mixing are working together, leading to strong ageostrophic westerlies (green arrow). In contrast, south of the low-SLP wedge, the surface friction and vertical mixing counteract each other with a small ageostrophic component (Fig. 5d). Therefore, the observed meridional change in ageostrophic wind across the K-KE front may be the result of both hydrostatic and vertical mixing effects working constructively north of the front and destructively to the south.

\section{b. Spring-summer season in ICOADS}

The prevailing winds in the western North Pacific change the direction from northwesterly to southwesterly during April (Fig. 1) when the subtropical high begins to form with a center at $30^{\circ} \mathrm{N}, 170^{\circ} \mathrm{E}$ (Fig. 6a). This subtropical high is well developed during summer (Fig. 6b). As expected from geostrophic balance, the surface winds are mostly south-southwesterlies and their speeds gradually weaken over the K-KE region from spring to summer, indicating the weak warm advection over the surface.

In the horizontal map of $Q$ (Fig. 6a), we find the strong surface heat flux regions over $75 \mathrm{~W} \mathrm{~m}^{-2}$ along the K-KE region from Taiwan through Japan into the KE. This is much like the northwesterly monsoon (Figs. 3a and 3b), except with reduced amplitudes of smaller $\Delta T_{\mathrm{OA}}$ and slower surface wind speed in spring than in autumn and winter (Fig. 6c). Unlike in the northwesterly monsoon, 


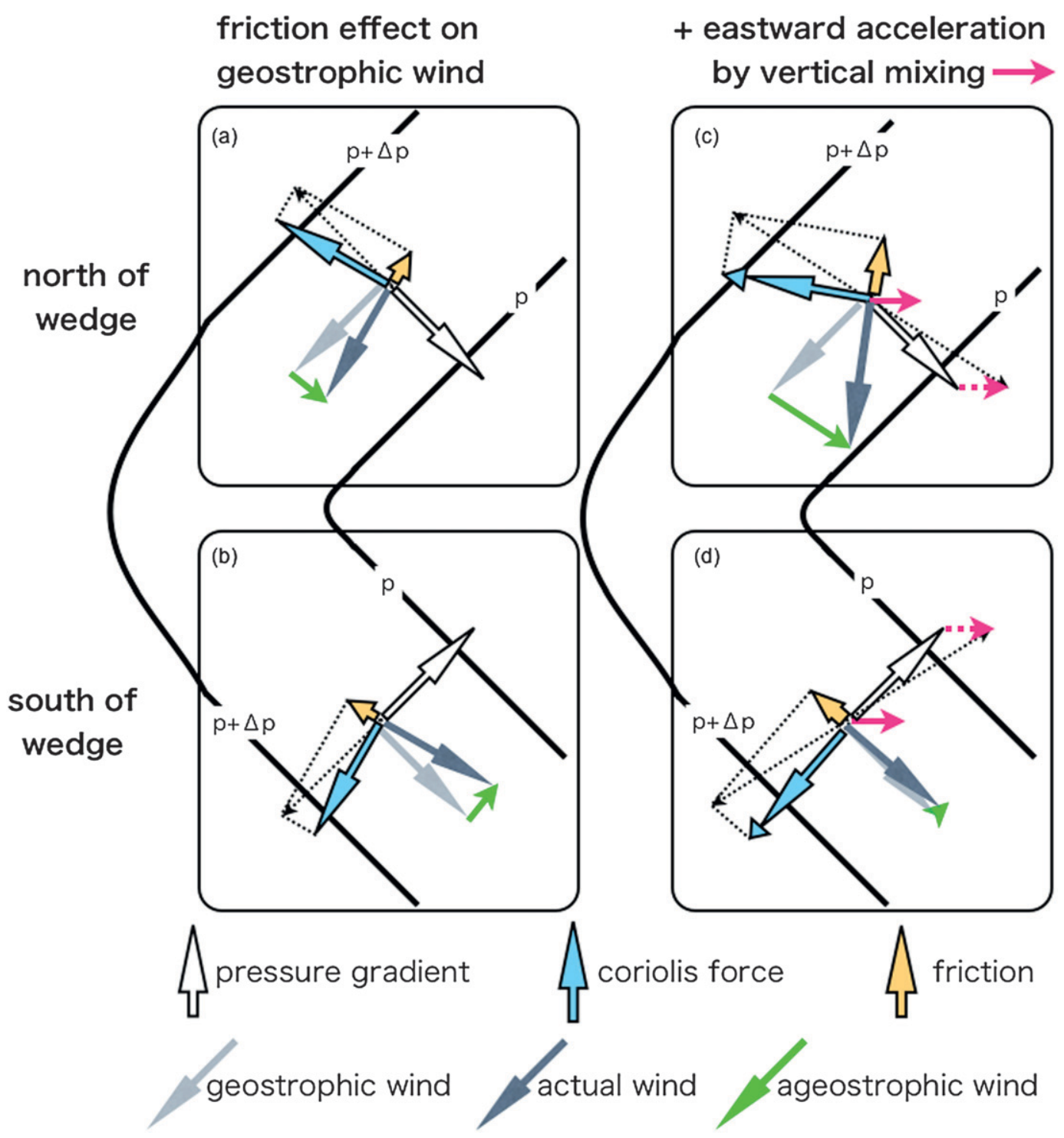

FIG. 5. Schematic figures of the surface momentum balance along the low-SLP wedge. (a),(b) Illustrated is the conventional friction effect on the geostrophic surface winds, which acts to push the air across the isobars from high to low pressure both (a) north and (b) south of the low-SLP wedge. (c) An additional eastward acceleration by the vertical mixing north of the low-SLP wedge acts to turn the pressure gradient to its left in the surface momentum balance. As a result, the actual surface wind will adjust by turning further left. (d) In contrast, south of the low-SLP wedge, the eastward acceleration acts on the pressure gradient to its right in the surface momentum balance. The wind will adjust by turning back toward the geostrophic wind.

however, the SLP field displays a low-SLP (1011.5$1013.5 \mathrm{hPa}$ ) wedge that extends eastward from Taiwan through Japan (white dashed line in Fig. 6a). As in the northwesterly monsoon, this eastward-extending wedge corresponds to an SLP trough over the large heat flux region. Ageostrophic northeasterlies are pronounced south of the eastward low-SLP wedge where $\Delta T_{\mathrm{OA}}<0.9^{\circ} \mathrm{C}$ (Fig. 7). Because of this near-neutral condition of surface static stability and associated weak surface heat flux, the vertical mixing is not as strong as during winter-spring seasons. Ageostrophic winds indicate large surface drag under near-neutral condition compared to unstable one. In the region under the unstable condition with $\Delta T_{\mathrm{OA}}>0.9^{\circ} \mathrm{C}$, the pressure gradient toward the west is counteracting the possible eastward acceleration induced by the vertical mixing. As a result, the ageostrophic winds weaken along the center axis of the lowSLP wedge. A distinct peak of $Q$ is not found during 


\section{Climatology}
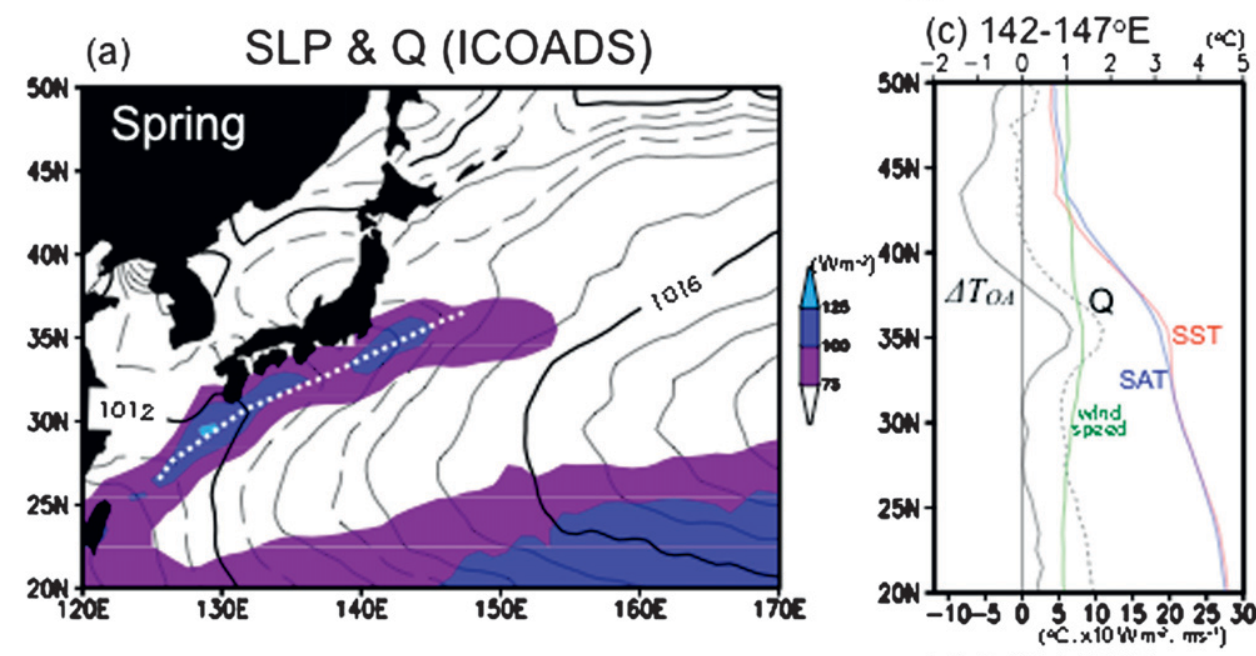

(e) $160-165^{\circ} \mathrm{E}$

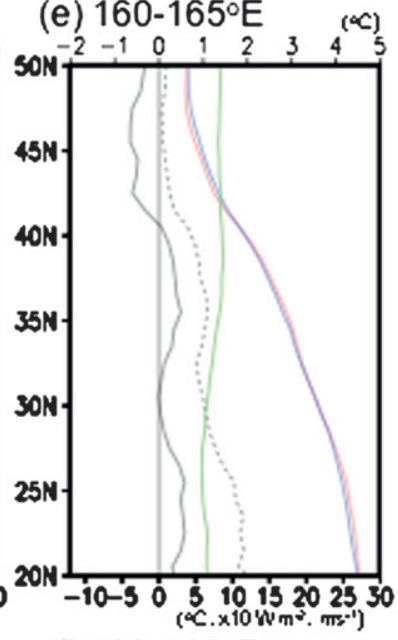

\section{(b) SLP \& Q (ICOADS)}

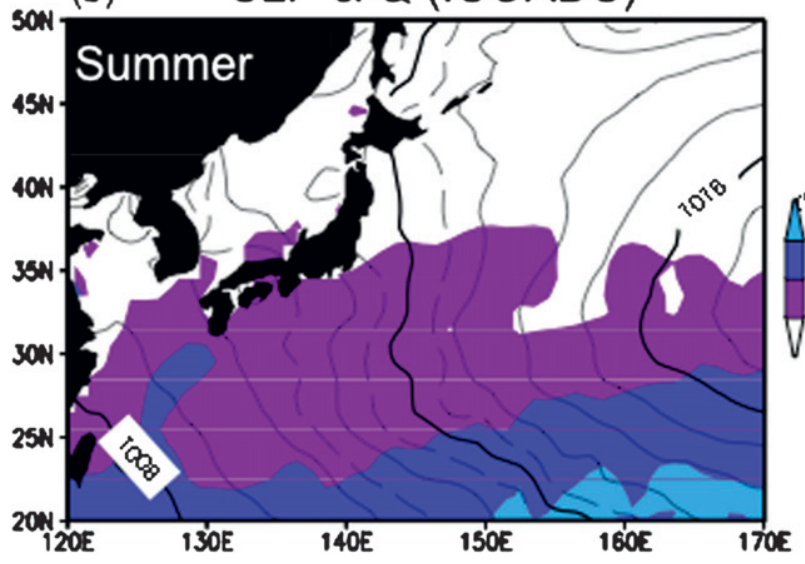

(d) $142-147^{\circ} \mathrm{E}$

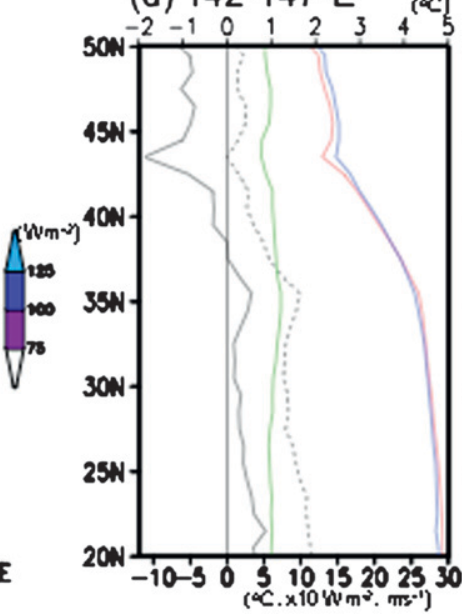

(f) $160-165^{\circ} \mathrm{E}$

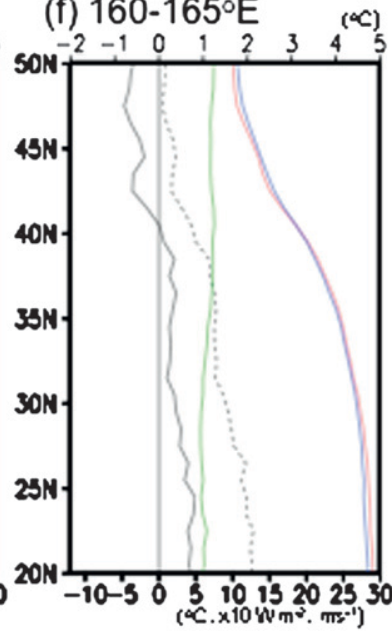

FIG. 6. As in Fig. 3, but for (a),(c),(e) spring, and (b),(d),(f) summer climatologies based on ICOADS. (a),(b) Seasonal-mean SLP (black contours; $\mathrm{CI}=1 \mathrm{hPa}$ ) and $Q$ (colors; $\mathrm{W} \mathrm{m}^{-2}$ ). Supplemental dashed contours at 0.5 -hPa intervals are plotted. White dashed line indicates the SLP trough in the K-KE region. Coloring convention is given to the right of each panel. (c), (d) Climatological SST (red; $\left.{ }^{\circ} \mathrm{C}\right), \mathrm{SAT}(\mathrm{blue}$; ${ }^{\circ} \mathrm{C}$ ), surface wind speed (green; $\mathrm{m} \mathrm{s}^{-1}$ ), $Q$ (dotted black; $10 \mathrm{~W} \mathrm{~m}^{-2}$ ), and $\Delta T_{\mathrm{OA}}$ (solid black; ${ }^{\circ} \mathrm{C}$ ) averaged over $142^{\circ}-147^{\circ} \mathrm{E}$. (e),(f) As in (c),(d), but for climatologies averaged over $160^{\circ}-165^{\circ} \mathrm{E}$. Note that the axis for $\Delta T_{\mathrm{OA}}$ is at the top of the panels, but the axis for the other variables is at the bottom of the panels.

summer (Fig. 6b), probably because strong solar radiation during summer weakens the frontal structure in SST along the K-KE region (Fig. 6d). As observed during autumn-winter seasons, no distinct peak of $Q$ is present in the interior region (Figs. 6e and 6f). The lack of a peak in $Q$ is not conducive to forming a local feature of the SLP.

Figure 8 shows the seasonal cycle of high-pass-filtered $Q$ and SLP anomalies, superimposed on the climatological surface winds averaged over $142^{\circ}-147^{\circ} \mathrm{E}$. For the high-pass filtering, we removed a spatial running mean of $5^{\circ}$ latitude over the ocean. It illustrates the phase relation of the meridional maximum in $Q$ and the SLP minimum along the $\mathrm{KE}$ region. The $Q$ maximum is anchored year-round at $35.5^{\circ} \mathrm{N}$ by the large $\Delta T_{\mathrm{OA}}$ along the $\mathrm{KE}$, as in the horizontal maps (Figs. 3 and 6). In the northerly or northwesterly monsoon during NovemberMarch, the SLP minimum is displaced southward by $1^{\circ}-2^{\circ}$ latitude by temperature advection of these climatological winds. Because of weak advection by the weak northwesterlies during October and southerlies during April-June, the SLP minimum is collocated with the $Q$ maximum.

\section{c. JRA-25}

Most in situ ship reports in ICOADS were instantaneously transmitted to the national weather services such as 


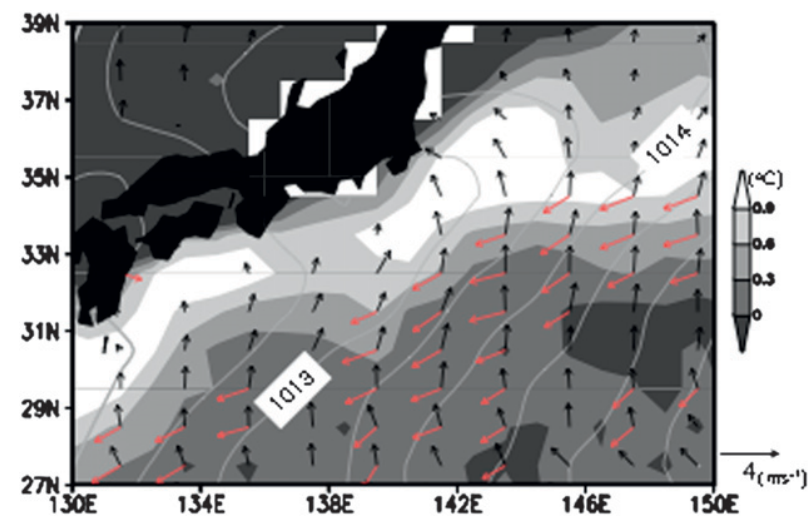

FIG. 7. Spring (April-June) climatology of surface wind (black arrows; $\mathrm{m} \mathrm{s}^{-1}$ ), and ageostrophic wind (red arrows; $\mathrm{m} \mathrm{s}^{-1}$ ), superimposed on SLP (gray contours at $0.5 \mathrm{hPa}$ interval), and $\Delta T_{\mathrm{OA}}$ (gray shades; ${ }^{\circ} \mathrm{C}$ ) based on ICOADS. Ageostrophic winds less than $3.5 \mathrm{~m} \mathrm{~s}^{-1}$ are not represented. Shading convention and scale of arrows are represented to the right.

the Japan Meteorological Agency (JMA) and the National Ocean and Atmosphere Administration (NOAA), and then incorporated into marine weather forecast. Atmospheric reanalysis assimilates all archived reports, and therefore is expected to represent the observed features, specifically over busy shipping lanes off the Pacific coast of the Japanese Islands. However a westwardextending low-SLP wedge over the K-KE region is found but much less pronounced in JRA-25 (Fig. 9) than in ICOADS (Fig. 3b). The intense heat flux over the K-KE is adequately represented in JRA-25 regarding its distribution and amplitude. While we will not pursue the exact cause of JRA-25 differences from ICOADS, we found, by analyzing other reanalysis datasets, that this problem is general, indicating problems of current assimilating AGCMs in representation of physics, especially those for MABL (Song et al. 2009).

\section{RAM experiment}

\section{a. Low-SLP wedge}

The previous section showed the westward-extending low-SLP wedge displaced slightly south of the local maximum of $Q$ and ageostrophic westerlies right over the $Q$ maximum. While these spatial relationships strongly indicate the oceanic influence on the overlying atmosphere via the hydrostatic and vertical mixing adjustments, the observational diagnosis alone cannot conclusively distinguish these ocean-to-atmosphere effects from atmosphere-to-ocean effects and midlatitude weather noise. We use the WRF to isolate SST frontal effects by comparisons of the CTRL and SMTH experiments. The experimental design was stated in section $2 \mathrm{c}$.

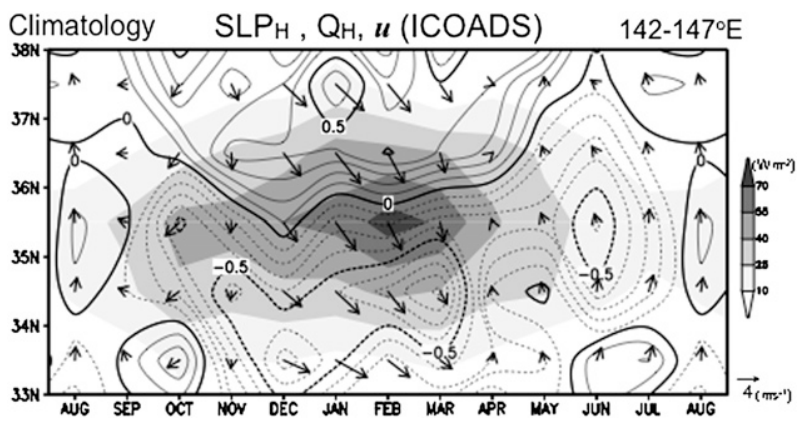

FIG. 8. Climatological seasonal cycle of high-pass-filtered SLP (contours; $\mathrm{CI}=0.1 \mathrm{hPa}$ ) and $Q$ (gray shades; $\mathrm{W} \mathrm{m}{ }^{-2}$ ) and surface wind vectors (arrows; $\mathrm{m} \mathrm{s}^{-1}$ ) averaged over $142^{\circ}-147^{\circ} \mathrm{E}$, based on ICOADS. Negative values are dashed. Note that the horizontal axis begins and ends in August. Shading convention and scale of arrows are given to the right.

Both CTRL and SMTH experiments using WRF (Figs. 10a and 10b) successfully reproduce the following large-scale features of the wintertime SLP field over the western North Pacific as observed in the JRA-25 (Fig. 10c). The SLP fields show a gradual westward increase north of $30^{\circ} \mathrm{N}$ associated with the northwesterly monsoon and a zonal ridge extending from the Yellow Sea at $35^{\circ} \mathrm{N}$, $120^{\circ} \mathrm{E}$ toward $25^{\circ} \mathrm{N}, 170^{\circ} \mathrm{E}$. Besides the large-scale features in SLP, the CTRL experiment is successful in capturing the westward-extending low-SLP wedge within the 1011-1016-hPa isobars over the region from Taiwan through Japan to the KE (Fig. 10a) where the strong $Q$ region with values over $500 \mathrm{~W} \mathrm{~m}^{-2}$ is simulated in a narrow $(\sim 500 \mathrm{~km})$ zonal band. The low-SLP wedge in the CTRL experiment is located slightly south of the maximum in $Q$ as observed. The magnitude of $Q$ in the CTRL experiment is 1.5-2 times larger than in the JRA-25 owing to the stronger SST front in AMSR-E, while the westward-extending low-SLP wedge is similar between

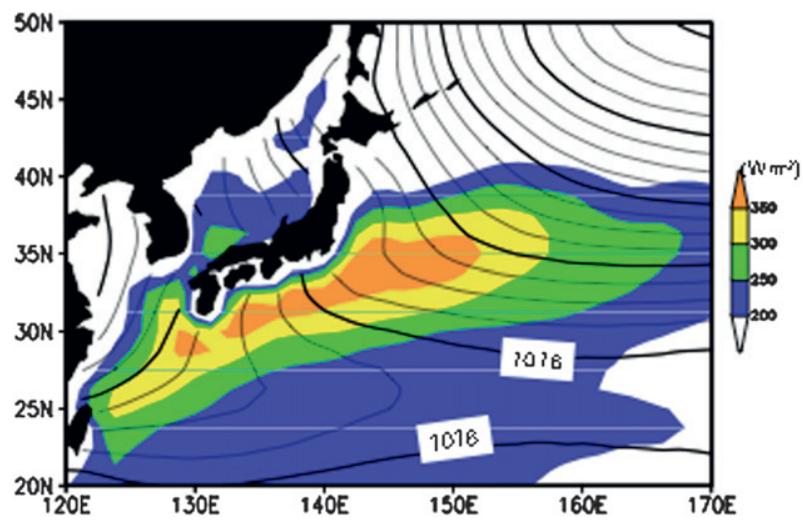

FIG. 9. Winter climatology of SLP (contours; $\mathrm{CI}=1 \mathrm{hPa}$ ) and $Q$ (colors; $\mathrm{W} \mathrm{m}^{-2}$ ) based on JRA-25. Shading convention and scale of arrows are given to the right of each panel. 
(a)
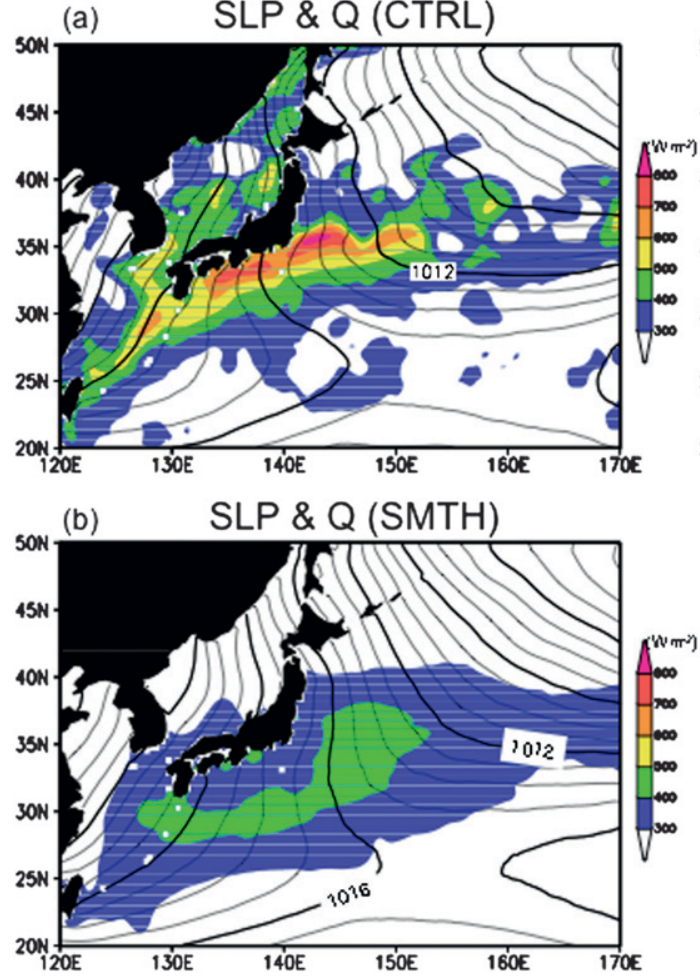

(c)

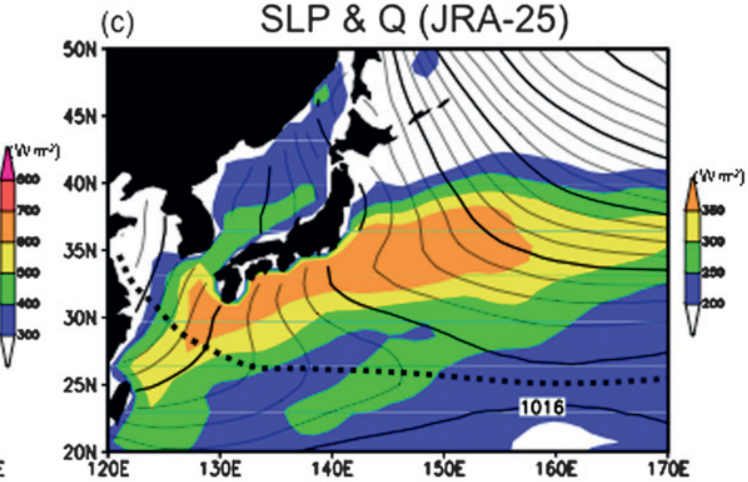

FIG. 10. Seasonal mean SLP (contours; CI $=1 \mathrm{hPa}$ ), $Q$ (colors; $\mathrm{W} \mathrm{m}^{-2}$ ) during the $2002 / 03$ winter in the (a) control and (b) smoothed-SST experiments using WRF. (c) As in (a), but for JRA-25. Black dotted line indicates the SLP ridge.

the CTRL experiment and JRA-25 but weaker than that in ICOADS. This result indicates that the MABL response to the intense surface heat flux in the K-KE region is still imperfect in the models (Tanimoto et al. 2009).

In the CTRL experiment, ageostrophic surface westerlies are significant only along the K-KE where surface heat flux is intense, as observed (Fig. 11a). We note that the simulated winds at the $850-\mathrm{hPa}$ level are mostly westerly as in the JRA-25 (not shown here). Because of the KE meander, the meridional maximum of $Q$ in $147^{\circ}-$ $148^{\circ} \mathrm{E}$ is located at $34^{\circ} \mathrm{N}$, slightly more southward than in the surrounding region. Ageostrophic surface westerlies tend to follow this meander. Following Takatama et al. (2011, manuscript submitted to Geophys Res. Lett.), we defined the vertical momentum transfer from aloft as residuals by removing the surface stress from the vertically integrated vertical mixing term in the lowest $100 \mathrm{~m}$. The difference in the vertical momentum transfer between the CTRL and SMTH experiments displays westerly acceleration over the region of intense surface heat flux along the K-KE region, indicative of enhanced vertical mixing (Fig. 11c). As observed, the ageostrophic westerlies are strong only north of the low-SLP wedge. The meridional plots averaged over $142^{\circ}-147^{\circ} \mathrm{E}$ show that the ageostrophic component is meridionally asymmetric against the meridionally symmetric change in $Q$ with a peak at $35^{\circ}-36^{\circ} \mathrm{N}$ (Fig. 11b). This result from the WRF experiments supports our hypothesis of four-way balance (Fig. 5), in which the westerly acceleration by vertical mixing and surface friction cooperates in forming the ageostrophic component north of the low-SLP wedge but counteracts against each other to its south. ${ }^{1}$

Figure 11d displays the differences in winter mean ageostrophic winds between the CTRL and SMTH experiments, superimposed on SLP and $Q$ in the SMTH experiment. The low-SLP wedge is less pronounced and ageostrophic westerlies are much weaker off the Pacific coast of Japan in the SMTH experiment than in the CTRL experiment because the narrow zonal band of strong surface heat flux disappears from the K-KE region. In the meridional plots averaged over $142^{\circ}-147^{\circ} \mathrm{E}$ (Fig. 11e), no significant peak is found either in the ageostrophic components or in $Q$. This drastic change in the local maximum of $Q$ is due to the reduced $\Delta T_{\mathrm{OA}}$ and moisture difference at the surface in the same region where the SST frontal structure is much reduced in the boundary condition for the SMTH experiment. Instead, a band of weak $Q$ maximum is found in the SMTH experiment in a region very far off the Pacific coast of Japan from $28^{\circ} \mathrm{N}, 130^{\circ} \mathrm{E}$ through $30^{\circ} \mathrm{N}, 142^{\circ} \mathrm{E}$ to $36^{\circ} \mathrm{N}, 147^{\circ} \mathrm{E}$. Over and/or south of the band,

\footnotetext{
${ }^{1}$ In the surface momentum budget in the WRF experiments, the pressure gradient, Coriolis force, friction, and vertical mixing terms are dominant in the K-KE region. Other terms such as horizontal and vertical advection are small.
} 


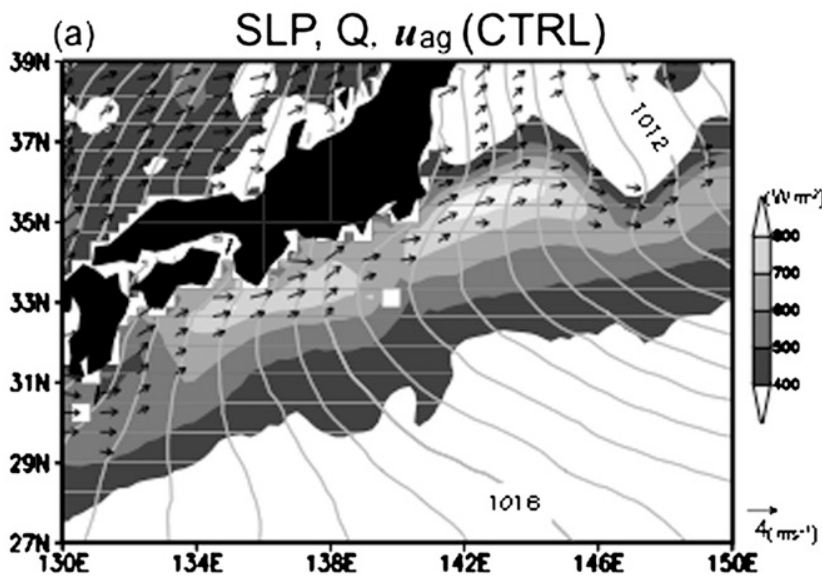

(b) $142-147^{\circ} \mathrm{E}$

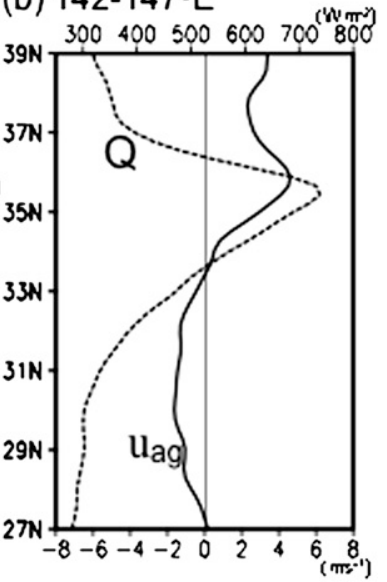

(C)SLP. Q(CTRL), vertical momentum transfer (CTRL-SMTH)

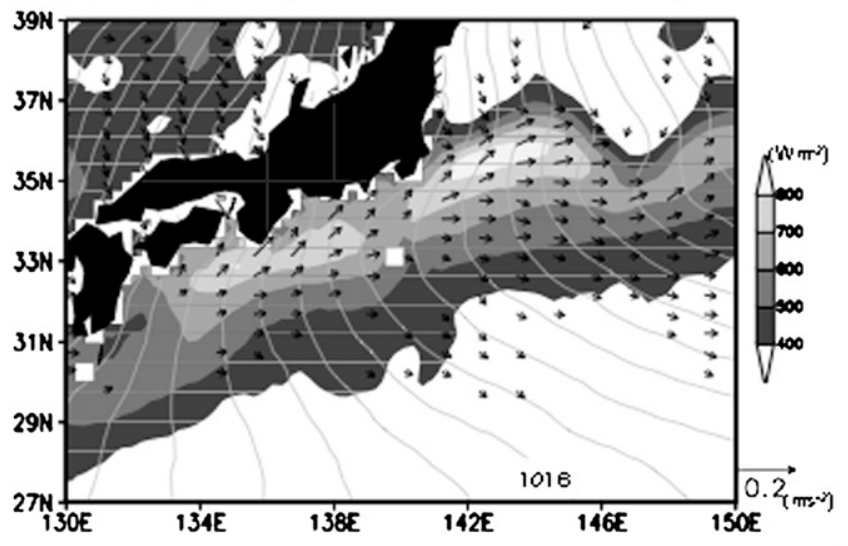

(d) SLP, Q(SMTH), $\boldsymbol{u}_{\mathrm{ag}}(\mathrm{CTRL}$ - SMTH)

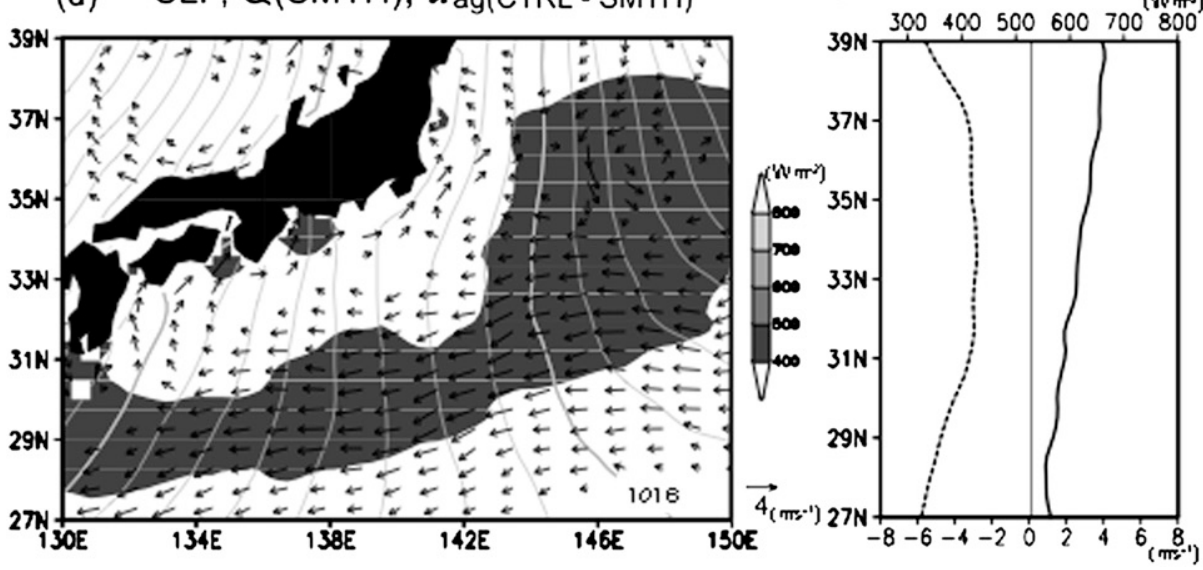

FIG. 11. Winter mean of WRF experiments: (a) ageostrophic wind (black arrows; $\mathrm{m} \mathrm{s}^{-1}$ ), superimposed on SLP (gray contours $\mathrm{CI}=0.5 \mathrm{hPa}$ ) and $Q$ (gray shades; $\mathrm{W} \mathrm{m}^{-2}$ ) in the control experiment. Ageostrophic winds less than $3.0 \mathrm{~m} \mathrm{~s}^{-1}$ are not represented. (b) Meridional plots of ageostrophic zonal wind (solid; $\mathrm{m} \mathrm{s}^{-1}$ ) and $Q$ (dashed; $\mathrm{W} \mathrm{m}^{-2}$ ) averaged over $142^{\circ}-147^{\circ} \mathrm{E}$ in the control experiment. Note that the axis for $Q$ is at the top of the panel, but the axis for the ageostrophic zonal winds is at the bottom of the panel. (c) Vertical momentum transfers from aloft (black arrows; $\mathrm{m} \mathrm{s}^{-2}$ ) between the control and smoothed experiments, superimposed on SLP (gray contours; CI $=0.5 \mathrm{hPa}$ ) and $Q$ (gray shades; $\mathrm{W} \mathrm{m}{ }^{-2}$ ) in the control experiment. Vertical momentum transfers less than $0.05 \mathrm{~m} \mathrm{~s}^{-2}$ are not represented. (d) Differences in ageostrophic winds (black arrows; $\mathrm{m} \mathrm{s}^{-1}$ ) between the control and smoothed experiments, superimposed SLP (gray contours; CI $=0.5 \mathrm{hPa}$ ), and $Q$ (gray shades; $\mathrm{W} \mathrm{m}^{-2}$ ) in the smoothed experiment. Wind differences less than $1.0 \mathrm{~m} \mathrm{~s}^{-1}$ are not represented. (e) As in (b), but for the smoothed experiment. Shading convention and scale of arrows are given on the right. 

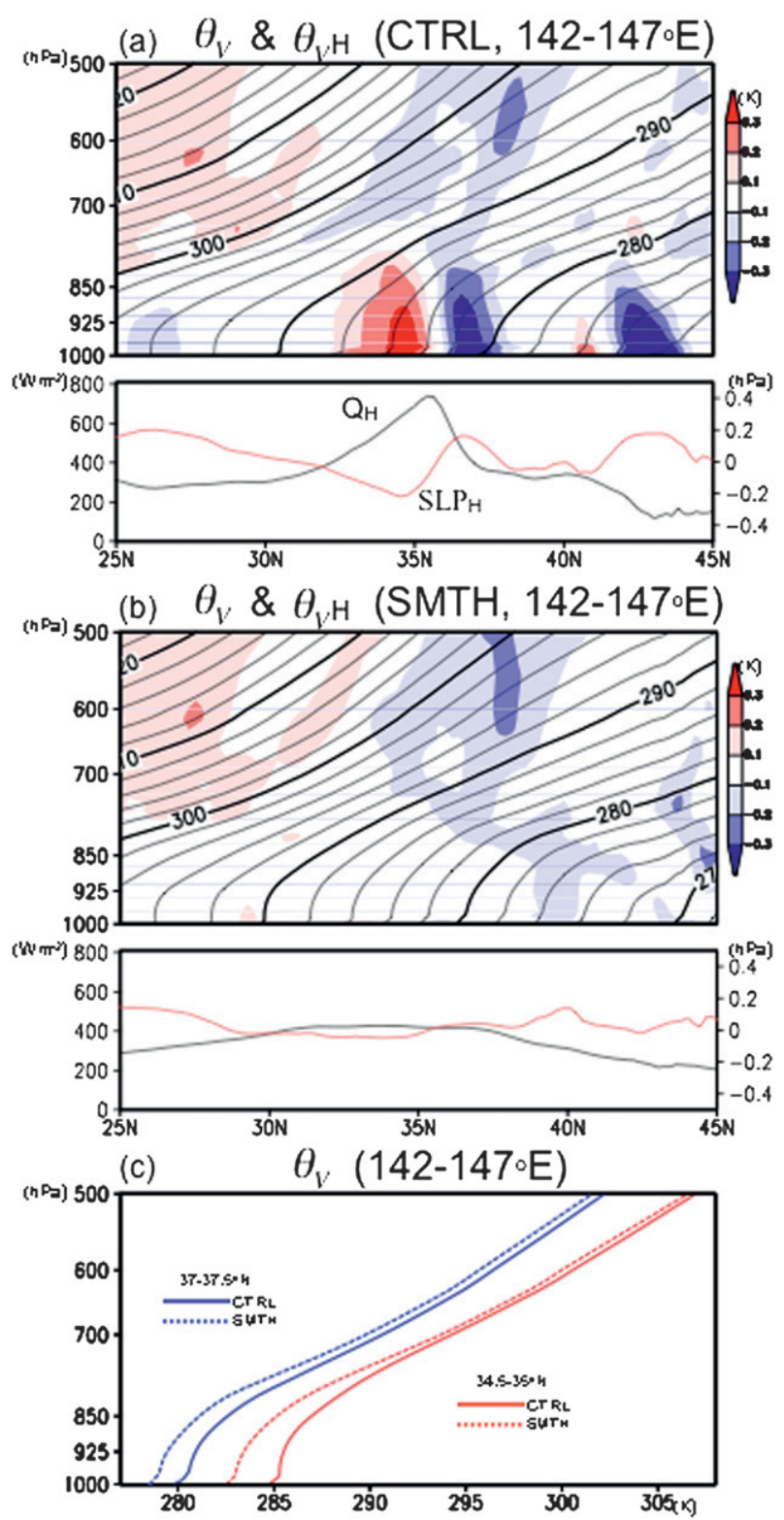

FIG. 12. (a, top) Meridional vertical cross section of winter mean $\theta_{V}$; contours; $\mathrm{CI}=2 \mathrm{~K}$ ) and its high-pass-filtered spatial anomalies (colors; K) averaged over $142^{\circ}-147^{\circ} \mathrm{E}$ in the control experiment. (a, bottom): Meridional plots of winter-mean $Q$ (black; $\mathrm{W} \mathrm{m}^{-2}$ ) and high-pass-filtered spatial SLP anomalies (red; hPa). Note that the axis for $Q$ is at the left of the panel, but the axis for the SLP anomalies is at the right of the panel. (b) As in (a), but for the smoothed experiment. (c) Vertical profiles of winter mean $\theta_{V}$ averaged over $34.5^{\circ}-35^{\circ} \mathrm{N}$ (red) and $37^{\circ}-37.5^{\circ} \mathrm{N}$ (blue) in the $142^{\circ}-$ $147^{\circ} \mathrm{E}$ section. The solid (dashed) lines denote the profile in the control (smoothed) experiment.

a weak westward-extending low-SLP wedge and anomalous easterlies in ageostrophic surface winds (enhanced ageostrophic surface westerlies in the SMTH experiment) are found in Fig. 11d. These results show that the SST frontal structure is necessary for the formation of the westward-extending low-SLP wedge and ageostrophic westerlies along the K-KE region.

In the meridional vertical section of the $142^{\circ}-147^{\circ} \mathrm{E}$ band, a local MABL response to the strong heat flux from the ocean is found across the front near $35^{\circ} \mathrm{N}$ in the CTRL experiment (Fig. 12a). High-pass-filtered spatial anomalies of virtual potential temperature $\theta_{V}$ in the CTRL experiment are positive (negative) up to the $850-\mathrm{hPa}$ level from the surface in $33^{\circ}-35^{\circ} \mathrm{N}\left(36^{\circ}-38^{\circ} \mathrm{N}\right)$. The positive anomalies are located slightly south of the peak in $Q$, rather than over it. This displacement results from the advection by the strong northerly winds in climatology, as in the tropical simulations of Small et al. (2003, 2005). No significant high-pass-filtered $\theta_{V}$ anomaly is presented in the SMTH experiment (Fig. 12b) due to the lack of the significant peak in $Q$ in the meridional direction. The vertical profiles of $\theta_{V}$ in Fig. 12c shows that the vertical gradient in the MABL south of $35^{\circ} \mathrm{N}$ is much weaker in the CTRL experiment than in the SMTH experiment, but the gradient difference between the two experiments is not so large north of $37^{\circ} \mathrm{N}$. This cross-frontal change in the MABL response indicates that the significant peak in $Q$ is key to developing the warm, wellmixed, and thick MABL that eventually forms the SLP minimum on the same location.

The only difference in the model setting between the CTRL and SMTH experiments is the surface boundary condition with and without the SST frontal structure, respectively. The results from the experiments show that the SST frontal structure affects the overlying atmosphere by the strong heat flux south of the front at $34.5^{\circ} \mathrm{N}$ (Fig. 12a). The atmosphere adjusts hydrostatically to the surface heat flux and lowers the SLP by $0.2 \mathrm{hPa}$ (Fig. $12 \mathrm{a}$ ) in the same region. Under the hydrostatic balance, this value of the SLP decrease is mostly explained by the high-pass-filtered positive temperature anomalies from the surface up to $850 \mathrm{hPa}$. In addition, enhanced vertical mixing in the warmed MABL along with the surface friction induces significant ageostrophic westerlies north of the low-SLP wedge (Fig. 11a).

\section{b. Possible effect of the SST front on storms}

Previous AGCM experiments reveal that strong sensible and latent heat fluxes along the extratropical SST front maintain the baroclinicity (Brayshaw et al. 2008; Nakamura et al. 2008; Nonaka et al. 2009). In addition, RAM experiments show that the associated moisture supplies can help energize midlatitude synoptic disturbances and thereby increase precipitation along the SST front (Taguchi et al. 2009; Iizuka 2010). To examine these effects of the SST front onto the midlatitude storm, we analyzed the precipitation field in the experiment. In the 
(a)

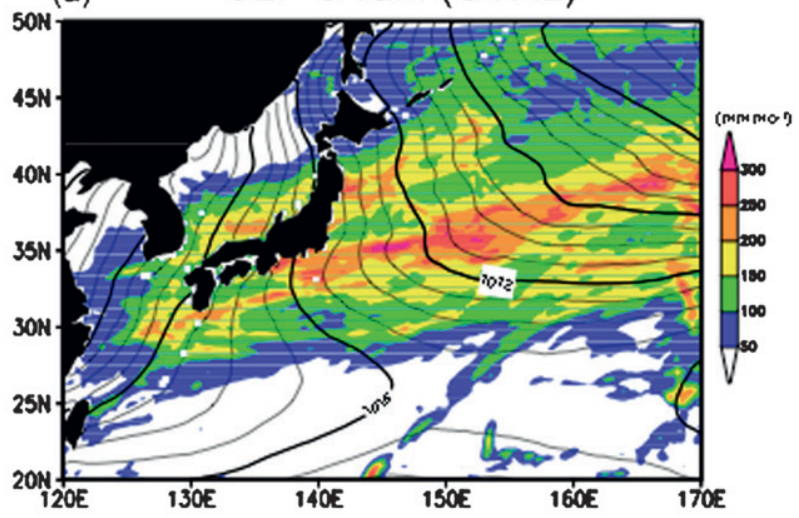

(b) SLP(CTRL) \& rain(CTRL-SMTH)

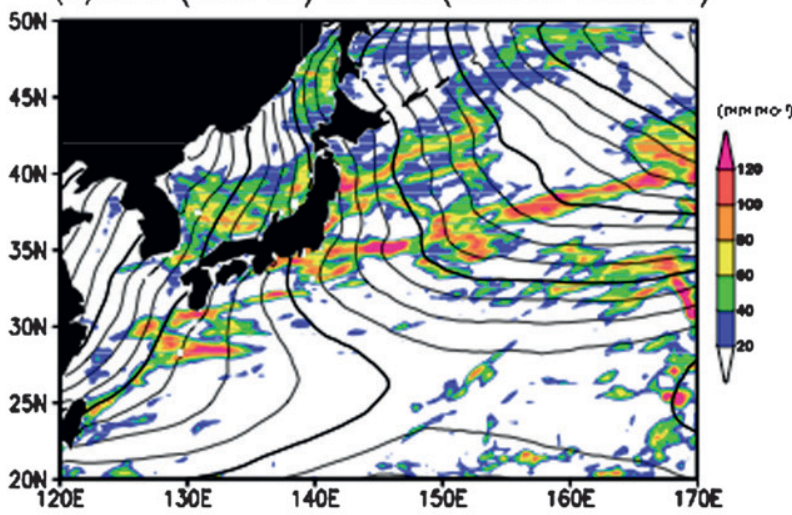

(c)SLP(CTRL) \& $\sigma_{\text {rain }}(C T R L-S M T H)$

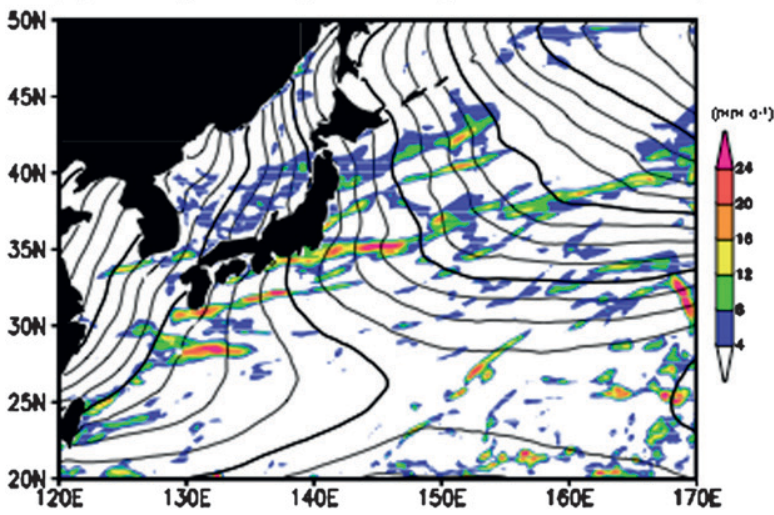

FIG. 13. Winter mean SLP (contours; CI $=1 \mathrm{hPa}$ ) and (a) accumulated rainfall (colors; $\mathrm{mm}$ month $^{-1}$ ) in the control experiment. (b) Differences in the simulated winter mean rainfall between the control and smoothed experiments (colors; mm month ${ }^{-1}$ ), and (c) differences in their standard deviations $\left(\mathrm{mm} \mathrm{day}^{-1}\right)$.

winter mean of the CTRL experiment (Fig. 13a), a zonal band of precipitation, with a meridional length of about $5^{\circ}$ latitude, extends east-northeastward from the Pacific coast of Japan into $40^{\circ} \mathrm{N}, 170^{\circ} \mathrm{E}$. While the similar rainband is simulated in the SMTH experiment (not shown), the rainfall intensity is different between them. A coherent narrow $\left(1^{\circ}-2^{\circ}\right.$ latitude length) band of increased rainfall over $80 \mathrm{~mm} \mathrm{month}^{-1}$ is found north of the lowSLP wedge in the CTRL experiment (Fig. 13b). In addition, the intraseasonal variance is larger in the CTRL than in the SMTH experiment (Fig. 13c), indicating some enhanced storms passing by along the rainband. The results indicate that intense surface heat flux along the SST front could influence the storm activity passing eastward over the K-KE. In the climatology, however, intensity of the storm activity is generally strong at the entrance of the Pacific jet stream in the midlatitudes $\left(30^{\circ}-\right.$ $\left.40^{\circ} \mathrm{N}\right)$. Therefore, it is still unclear whether the collocation of the strong $Q$ across the SST front and active storm-track activity is by chance or the consequence of the atmospheric response to the SST front. The present study indicates that the SST front intensifies the overlying rainband even though the rainband itself may be originally formed by any other reason. Adachi and Kimura (2007) pointed out that the cyclogenesis is intense along the Pacific coast of Japan. Lower SLP and weaker stability of the MABL along the SST front, compared to its surrounding areas, can be favorable for the development of cyclones that involve the upper trough. If it is the case, we will investigate, in the future, how the growth of storms along the SST front contributes to the climatological low-SLP wedge.

\section{Summary and discussion}

We have investigated the spatial characteristics of the climatological SLP and surface wind fields in the western North Pacific where the monsoonal flow is pronounced. In our analyses, in situ marine observations of ICOADS are employed along with the JRA-25 reanalysis and the RAM simulations. Previous in situ atmospheric soundings across the SST front along the Kuroshio and its extension (K-KE) revealed transitions of the MABL structure including its height, temperature, moisture, wind, and cloud regime (Tokinaga et al. 2006; Tanimoto et al. 2009; Tokinaga et al. 2009), suggesting both hydrostatic and vertical mixing effects in the MABL. Therefore, our focus is how these frontal effects modify the monsoons.

In the winter climatology, a westward-extending lowSLP wedge is evident in SLP contours, displaced slightly south of the zonal band of strong surface heat flux $Q$ along the K-KE (Fig. 3b). The steep SST front maintains a distinct peak of temperature difference between the ocean and atmosphere $\Delta T_{\mathrm{OA}}$. The low-SLP wedge in the unfiltered field strongly indicates the hydrostatic effect along the SST front as found in high-pass-filtered SLP field by Tokinaga et al. (2009) and Xu et al. (2010) along the K-KE region and Minobe et al. (2008, 2010) along the Gulf Stream. The southward shift of the low-SLP wedge from 
the $Q$ peak is probably due to thermal advection by the mean northwesterlies, as shown in the equatorial region by Small et al. $(2003,2005)$. While weak easterlies are expected from geostrophy north of the low-SLP wedge, the observed surface winds are northwesterlies with a crossbaric component toward the center axis of the low-SLP wedge. This result indicates an eastward acceleration due to enhanced vertical mixing of the midlatitude westerlies from aloft along the band of strong $Q$, leading to a northwesterly ageostrophic component in the presence of surface friction (Fig. 5c). In contrast, the observed winds are mostly geostrophic south of the low-SLP wedge where vertical mixing and friction work against each other (Fig. 5d). Albeit slightly weaker in magnitude, the autumn climatology displays similar spatial features. These observational findings indicate that the intense surface heat flux heats the MABL over the K-KE region, lowering the local SLP by a hydrostatic adjustment.

To examine the effect of the SST front on the overlying MABL, we conduct regional atmospheric model (RAM) experiments using nonhydrostatic and highresolution WRF model for winter 2002/03. In the control (CTRL) experiment with the prescribed high-resolution SST on a $0.25^{\circ}$ grid, the westward-extending low-SLP wedge and ageostrophic westerlies north of it are well simulated along the K-KE. The intense surface heat flux is simulated over the SST front, albeit its amplitude is 1.5-2 times larger than the observed. In contrast, in the smoothed (SMTH) experiment that weakens the SST front, the band of intense heat flux along the K-KE and low-SLP wedge are not represented. These results support the ideas that the SST frontal structure along the $\mathrm{K}-\mathrm{KE}$ is important for the strong heat flux, and that the heat flux heats the MABL, lowers the SLP locally, and produces the ageostrophic westerlies through enhanced vertical mixing.

Despite assimilating in situ observations, the low-SLP wedge in the JRA-25 climatology is weak compared to the ICOADS climatology. The MABL response across the SST front in AGCMs used for the assimilation should be carefully examined. An important implication from the low-SLP wedge in the reanalysis data is that not all observational datasets contain this low-SLP wedge pattern except in the climatology from ICOADS and hence our understanding on their interannual characteristics is still highly limited. Longer-term numerical model simulations are necessary to assess the local and larger-scale impact of this regional SLP pattern arising from the fronts on the atmosphere.

In spring climatology, the surface heat flux is still strong along the K-KE. Because the temperature in the ocean and the atmosphere is not still completely in equilibrium, the resultant low-SLP wedge extending eastward and ageostrophic winds are found even under the southwesterly monsoonal flow. In the seasonal cycle along the KE, the meridional maximum of $Q$ is anchored at $35.5^{\circ} \mathrm{N}$ where the KE front maintains large $\Delta T_{\mathrm{OA}}$ year round. The SLP minimum (center of the low-SLP wedge) shows a meridional migration, displaced south of the front during the northwesterly monsoon and collocated with the KE front during the southwesterly monsoon. This spatial relation of SLP and $Q$ is due to thermal advection by the mean winds. Thus, the low-SLP wedge and ageostrophic winds are observed not only off the Pacific coast but also along the KE region that is far $(800-1000 \mathrm{~km})$ from the Japanese islands from autumn to spring regardless of the change in monsoonal wind. The RAM successfully reproduces those atmospheric adjustments in the CTRL experiment but fails in the SMTH experiment. If the orographic effect were a major factor for the pressure minimum, the SMTH experiment would simulate the low-SLP wedge along the Pacific coast of Japan. As in section 4, it is not the case in our experiments (Fig. 10b). Ageostrophic winds in the CTRL experiment are simulated all the way from $130^{\circ}$ to $150^{\circ} \mathrm{E}$ along the K-KE and follow the local maximum of $Q$ along the KE meander (Fig. 11a). These results indicate that the atmospheric adjustments are caused by intense heat flux along the K-KE, rather than by the orographic effect of high mountains on Japanese islands.

Acknowledgments. The authors wish to thank Drs. H. Nakamura, B. Taguchi, M. Nonaka, M. Kimoto, H. Mukougawa, M. Watanabe, S. Adachi, and K. Takatama for useful discussions, and M. Xu and H. Xu for providing the WRF codes for momentum budget analysis. We are also grateful to three anonymous reviewers for their constructive comments, which helped improve the manuscript. This work was supported in part by the Global Environment Research Fund (S-5) of the Ministry of the Environment, Japan, Grand-In-Aid for Scientific Research defrayed by the Ministry of Education, Culture, Sports, Science and Technology of Japan (18204044, 22340132, 22340135, 22106007), NOAA, NASA, and JAMSTEC.

\section{REFERENCES}

Adachi, S., and F. Kimura, 2007: A 36-year climatology of surface cyclogenesis in East Asia using high-resolution reanalysis data. SOLA, 3, 113-116.

Betts, A. K., and M. J. Miller, 1986: A new convective adjustment scheme. Part II: Single column tests using GATE wave, BOMEX, ATEX and arctic air-mass data sets. Quart. J. Roy. Meteor. Soc., 112, 693-709.

Brayshaw, D. J., B. Hoskins, and M. Blackburn, 2008: The stormtrack response to idealized SST perturbations in an aquaplanet GCM. J. Atmos. Sci., 65, 2842-2860. 
Chelton, D. B., M. G. Schlax, M. H. Freilich, and R. F. Milliff, 2004: Satellite measurements reveal persistent small-scale features in ocean winds. Science, 303, 978-983.

Cronin, M. F., S.-P. Xie, and H. Hashizume, 2003: Barometric pressure variations associated with eastern Pacific tropical instability waves. J. Climate, 16, 3050-3057.

Deser, C., M. A. Alexander, and M. S. Timlin, 1996: Upper-ocean thermal variations in the North Pacific during 1970-1991. J. Climate, 9, 1840-1855.

Dudhia, J., 1989: Numerical study of convection observed during the winter monsoon experiment using a mesoscale twodimensional model. J. Atmos. Sci., 46, 3077-3107.

Hashizume, H., S.-P. Xie, M. Fujiwara, M. Shiotani, T. Watanabe, Y. Tanimoto, W. T. Liu, and K. Takeuchi, 2002: Direct observations of atmospheric boundary layer response to SST variations associated with tropical instability waves over the eastern equatorial Pacific. J. Climate, 15, 3379-3393.

Hayes, S. P., M. J. McPhaden, and J. M. Wallace, 1989: The influence of sea surface temperature on surface wind in the eastern equatorial Pacific: Weekly to monthly variability. J. Climate, 2, 1500-1506.

Hong, S.-Y., and J.-O. J. Lim, 2006: The WRF single-moment 6class microphysics scheme (WSM6). J. Korean Meteor. Soc., 42, 129-151.

Iizuka, S., 2010: Simulations of wintertime precipitation in the vicinity of Japan: Sensitivity to fine-scale distributions of SST J. Geophys. Res., 117, D10107, doi:10.1029/2009JD012576.

Janjić, Z. I., 1994: The step-mountain eta coordinate model: Further developments of the convection, viscous sublayer, and turbulence closure schemes. Mon. Wea. Rev., 122, 927-945.

Kleeman, R., and S. B. Power, 1995: A simple atmospheric model of surface heat flux for use in ocean modeling studies. J. Phys. Oceanogr., 25, 92-105.

Kubota, M., N. Iwasaka, S. Kizu, M. Konda, and K. Kutsuwada, 2002: Japanese ocean flux data sets with use of remote sensing observations (J-OFURO). J. Oceanogr., 58, 213-225.

Lindzen, R. S., and S. Nigam, 1987: On the role of sea surface temperature gradients in forcing low-level winds and convergence in the Tropics. J. Atmos. Sci., 44, 2418-2436.

Minobe, S., A. Kuwano-Yoshida, N. Komori, S.-P. Xie, and R. J. Small, 2008: Influence of the Gulf Stream on the troposphere. Nature, 452, 206-209.

_- M. Miyashita, A. Kuwano-Yoshida, H. Tokinaga, and S.-P. Xie, 2010: Atmospheric response to the Gulf Stream: Seasonal variations. J. Climate, 23, 3699-3719.

Mlawer, E. J., S. J. Taubman, P. D. Brown, M. J. Iacono, and S. A. Clough, 1997: Radiative transfer for inhomogeneous atmospheres: RRTM, a validated correlated-k model for the longwave. J. Geophys. Res., 102, 16 663-16 682.

Nakamura, H., T. Sampe, A. Goto, W. Ohfuchi, and S.-P. Xie, 2008: On the importance of midlatitude oceanic frontal zones for the mean state and dominant variability in the tropospheric circulation. Geophys. Res. Lett., 35, L15709, doi:10.1029/ $2008 \mathrm{gl} 1034010$.

Nonaka, M., H. Nakamura, B. Taguchi, N. Komori, A. KuwanoYoshida, and K. Takaya, 2009: Air-sea heat exchanges characteristic of a prominent midlatitude oceanic front in the south Indian Ocean as simulated in a high-resolution coupled GCM. J. Climate, 22, 6515-6535.

O'Neill, L. W., D. B. Chelton, and S. K. Esbensen, 2003: Observations of SST-induced perturbations of the wind stress field over the Southern Ocean on seasonal timescales. J. Climate, 16, 2340-2354.
,,,--- and F. J. Wentz, 2005: High-resolution satellite measurements of the atmospheric boundary layer response to SST variations along the Agulhas Return Current. J. Climate, 18, 2706-2723.

,-- , and -2010 : The effects of SST-induced surface wind speed and direction gradients on midlatitude surface vorticity and divergence. J. Climate, 23, 255-281.

Onogi, K., and Coauthors, 2007: The JRA-25 Reanalysis. J. Meteor. Soc. Japan, 85, 369-432.

Park, K.-A., P. Cornillon, and D. L. Codiga, 2006: Modification of surface winds near ocean fronts: Effects of Gulf Stream rings on scatterometer (QuikSCAT, NSCAT) wind observations. J. Geophys. Res., 111, C03021, doi:10.1029/2005jc003016.

Pleim, J. E., and J. S. Chang, 1992: A non-local closure model for vertical mixing in the convective boundary layer. Atmos. Environ., 26A, 965-981.

Raymond, D. J., and Coauthors, 2004: EPIC2001 and the coupled ocean-atmosphere system of the tropical east Pacific. Bull. Amer. Meteor. Soc., 85, 1341-1354.

Reynolds, R. W., T. M. Smith, C. Liu, D. B. Chelton, K. S. Casey, and M. G. Schlax, 2007: Daily high-resolution-blended analyses for sea surface temperature. J. Climate, 20, 5473-5496.

Schneider, N., A. J. Miller, M. A. Alexander, and C. Deser, 1999: Subduction of decadal North Pacific temperature anomalies: Observations and dynamics. J. Phys. Oceanogr., 29, 10561070.

Skamarock, W. C., J. B. Klemp, J. Dudhia, D. M. Barker, M. G. Duda, X.-Y. Huang, W. Wang, and J. G. Powers, 2008: A description of the Advanced Research WRF version 3. NCAR Tech. Note NCAR/TN-475+STR, 113 pp.

Small, R. J., S.-P. Xie, and Y. Wang, 2003: Numerical simulation of atmospheric response to Pacific tropical instability waves. J. Climate, 16, 3723-3741.

,-- _ and J. Hafner, 2005: Satellite observations of mesoscale ocean features and copropagating atmospheric surface fields in the tropical belt. J. Geophys. Res., 110, C02021, doi:10.1029/ 2004 jc002598.

, and Coauthors, 2008: Air-sea interaction over ocean fronts and eddies. Dyn. Atmos. Oceans, 45, 274-319.

Song, Q., P. Cornillon, and T. Hara, 2006: Surface wind response to oceanic fronts. J. Geophys. Res., 111, C12006, doi:10.1029/ $2006 \mathrm{jc} 003680$.

— D. B. Chelton, S. K. Esbensen, N. Thum, and L. W. O'Neill, 2009: Coupling between sea surface temperature and lowlevel winds in mesoscale numerical models. J. Climate, 22, 146-164.

Suga, T., and K. Hanawa, 1995: The subtropical mode water circulation in the North Pacific. J. Phys. Oceanogr., 25, 958-970.

Sugimoto, S., and K. Hanawa, 2007: Impact of remote reemergence of the subtropical mode water on winter SST variation in the central North Pacific. J. Climate, 20, 173-186.

Taguchi, B., H. Nakamura, M. Nonaka, and S.-P. Xie, 2009: Influences of the Kuroshio-Oyashio Extensions on air-sea heat exchanges and storm-track activity as revealed in regional atmospheric model simulations for the 2003/04 cold season. J. Climate, 22, 6536-6560.

Tanimoto, Y., H. Nakamura, T. Kagimoto, and S. Yamane, 2003: An active role of extratropical sea surface temperature anomalies in determining anomalous turbulent heat flux. J. Geophys. Res., 108, 3304, doi:10.1029/2002jc001750.

— , S.-P. Xie, K. Kai, H. Okajima, H. Tokinaga, T. Murayama, M. Nonaka, and H. Nakamura, 2009: Observations of marine 
atmospheric boundary layer transitions across the summer Kuroshio Extension. J. Climate, 22, 1360-1374.

Tokinaga, H., Y. Tanimoto, and S.-P. Xie, 2005: SST-induced surface wind variations over the Brazil-Malvinas confluence: Satellite and in situ observations. J. Climate, 18, 34703482.

, and Coauthors, 2006: Atmospheric sounding over the winter Kuroshio Extension: Effect of surface stability on atmospheric boundary layer structure. Geophys. Res. Lett., 33, L04703, doi:10.1029/2005g1025102.

_- Y. Tanimoto, S.-P. Xie, T. Sampe, H. Tomita, and H. Ichikawa, 2009: Ocean frontal effects on the certical development of clouds over the western North Pacific: In situ and satellite observations. J. Climate, 22, 4241-4260.

Tomita, H., M. Kubota, M. F. Cronin, S. Iwasaki, M. Konda, and H. Ichikawa, 2010: An assessment of surface heat fluxes from J-OFURO2 at the KEO and JKEO sites. J. Geophys. Res., 115, C03018, doi:10.1029/2009jc005545.

Tourre, Y. M., Y. Kushnir, and W. B. White, 1999: Evolution of interdecadal variability in sea level pressure, sea surface temperature, and upper ocean temperature over the Pacific Ocean. J. Phys. Oceanogr., 29, 1528-1541.

Vecchi, G. A., S.-P. Xie, and A. S. Fischer, 2004: Ocean-atmosphere covariability in the western Arabian Sea. J. Climate, 17, 12131224.

Wallace, J. M., T. P. Mitchell, and C. Deser, 1989: The influence of sea surface temperature on surface wind in the eastern equatorial Pacific: Seasonal and interannual variability. J. Climate, 2, 1492-1499.

Wentz, F. J., and T. Meissner, 2000: Algorithm Theoretical Basis Document (ATBD) version 2: AMSR ocean algorithm. Remote Sensing Systems Tech. Rep. 121599A-1, 59 pp.

Worley, S. J., S. D. Woodruff, R. W. Reynolds, S. J. Lubker, and N. Lott, 2005: ICOADS release 2.1 data and products. Int. J. Climatol., 25, 823-842.

Xie, S.-P., 2004: Satellite observations of cool ocean-atmosphere interaction. Bull. Amer. Meteor. Soc., 85, 195-208.

Xu, H., H. Tokinaga, and S.-P. Xie, 2010: Atmospheric effects of the Kuroshio large meander during 2004-05. J. Climate, 23, 4704-4715. 